\title{
Methodology for Flight Relevant Arc-Jet Testing of Flexible Thermal Protection Systems
}

\author{
Alireza Mazaheri*, Walter E. Bruce III.* \\ NASA Langley Research Center, Hampton, VA 23681 \\ Nathaniel J. Mesick ${ }^{\ddagger}$ \\ Science Systems and Applications, Inc., Hampton, VA 23666 \\ Kenneth Sutton ${ }^{\mathrm{s}}$ \\ National Institute of Aerospace, Hampton, VA 23666
}

\begin{abstract}
A methodology to correlate flight aeroheating environments to the arc-jet environment is presented. For a desired hot-wall flight heating rate, the methodology provides the arcjet bulk enthalpy for the corresponding cold-wall heating rate. A series of analyses were conducted to examine the effects of the test sample model holder geometry to the overall performance of the test sample. The analyses were compared with arc-jet test samples and challenges and issues are presented. The transient flight environment was calculated for the Hypersonic Inflatable Aerodynamic Decelerator (HIAD) Earth Atmospheric Reentry Test (HEART) vehicle, which is a planned demonstration vehicle using a large inflatable, flexible thermal protection system to reenter the Earth's atmosphere from the International Space Station. A series of correlations were developed to define the relevant arc-jet test environment to properly approximate the HEART flight environment. The computed arcjet environments were compared with the measured arc-jet values to define the uncertainty of the correlated environment. The results show that for a given flight surface heat flux and a fully-catalytic TPS, the flight relevant arc-jet heat flux increases with the arc-jet bulk enthalpy while for a non-catalytic TPS the arc-jet heat flux decreases with the bulk enthalpy.
\end{abstract}

\section{Nomenclature}

A Arc-Jet aeroheating indicator correlation coefficient

C Flight aeroheating indicator correlation coefficient

$H \quad$ Total enthalpy, $\mathrm{MJ} / \mathrm{kg} \quad \rho$

$h \quad$ Enthalpy, $\mathrm{J} / \mathrm{kg}$

$P \quad$ Total pressure, pa

$\rho \quad$ Density, $\mathrm{kg} / \mathrm{m}^{3}$

$p \quad$ Pressure, pa

Subscripts

0

2

Heat flux, $\mathrm{W} / \mathrm{cm}^{2}$

$B$

$R \quad$ Radius

C

Entropy, J/kg-K

$N$

Temperature, $\mathrm{K}$

$w$

Velocity, m/sec

$\alpha$

$\infty$

Chamber or Stagnation

Post shock

Sample holder base

Sample holder corner

Sample holder nose

Wall

Angle-of-Attack

Free stream

*Corresponding author, Aerospace Engineer, Aerothermodynamics Branch, M/S 408A, Senior AIAA Member, Ali.R.Mazaheri@NASA.gov

†Thermal Engineer, Structural and Thermal System Branch M/S 431, AIAA Member

¥Test Engineer, Mechanical Systems Branch

$\S$ National Institute of Aerospace, M/S 408A, AIAA Associate Fellow 


\section{Introduction}

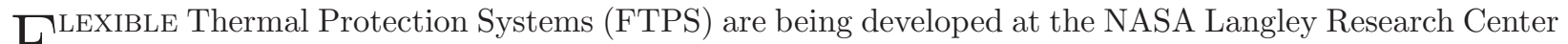
$\mathrm{F}$ for application on Hypersonic Inflatable Aerodynamic Decelerators (HIAD) to support future atmospheric entry missions. Ground testing is essential to develop and demonstrate the performance of new FTPS over a range of flight relevant conditions. In addition, ground testing also supports development of codes to calculate the Thermal Protection System (TPS) in-depth thermal response for various flight trajectories.

A substantial amount of ground testing has been performed in various facilities to support FTPS development and evaluation as described in References. ${ }^{1-3}$ Currently, arc-jet facilities are the only facilities that can provide flight relevant coupled aerothermal loads (heat flux, pressure, enthalpy, and shear) for flexible systems for durations sufficient to test over the total flight heat load. One of the major difficulties with ground testing is determining the appropriate arc-jet conditions and testing configuration to sufficiently approximate the flight loads. Verifying that the arc-jet facility is providing the appropriate test conditions is also challenging.

This paper introduces a methodology to estimate the flight relevant arc-jet heat flux and heat load. This technique is developed to predict the relationship between the flight and the arc-jet surface heat flux to better demonstrate the performance of a new FTPS, and therefore, predicting the actual arc-jet flow-field profile ahead of the test article was replaced with a representative free steam condition that satisfied the surface pressure, heat flux and the total heat load experienced by the FTPS. Because the performance of TPS is highly sensitive to the aerodynamic shear forces, surface pressure, and heat flux gradients, a TPS sample holder was specifically designed based on a range of heat flux and arc-jet facility constraints. The arc-jet sample holder and testing methodology are also introduced in this paper.

The paper is organized to first present the methodology that relates the arc-jet bulk enthalpies to flight hot-wall heating rates. The next section validates the methodology by comparing computed and measured arc-jet data for a proposed HEART FTPS. Then a particular flight application is chosen, the HEART vehicle, for which trajectory information is provided. The last section applies the present methodology to the HEART mission to obtain flight to arc-jet heating environment correlations as a function of the arc-jet operating bulk enthalpy.

\section{Context: Arc-Jet Operations}

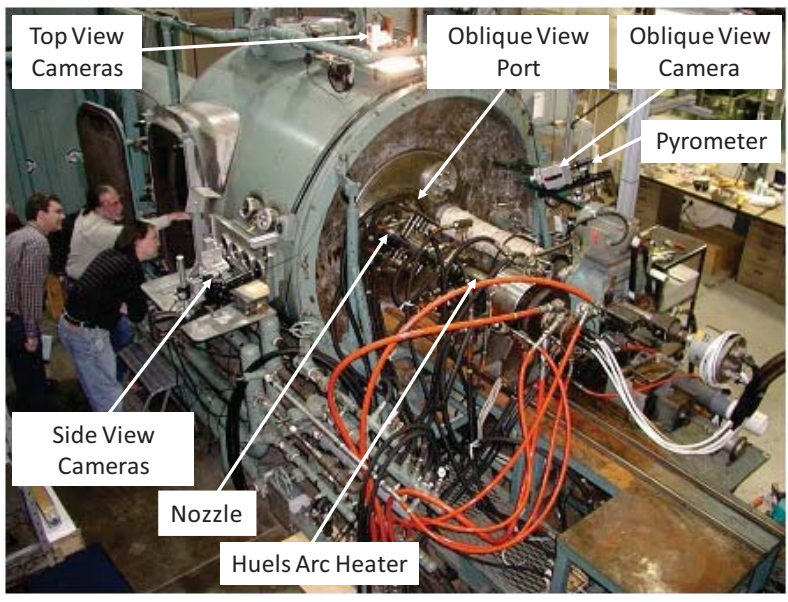

(a)

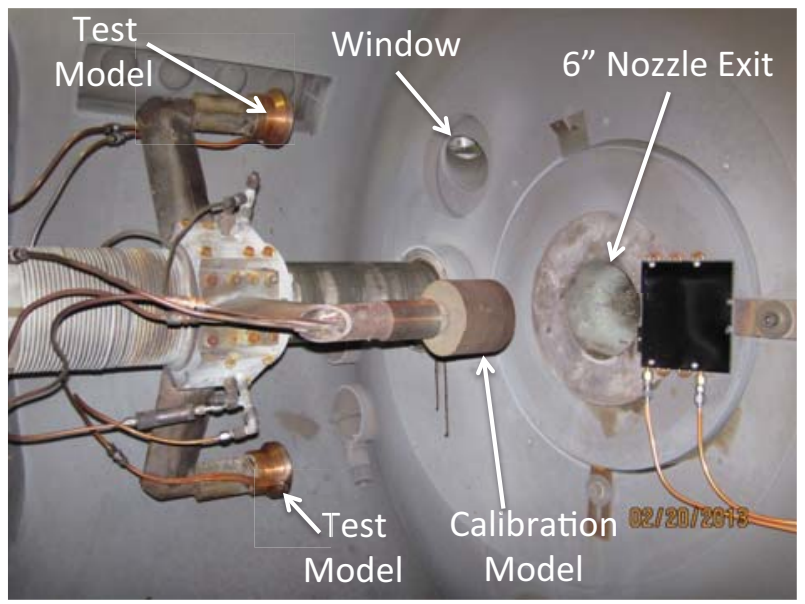

(b)

Figure 1. a) The Boeing Large Core Arc Tunnel (LCAT), and b) the test cabin interior and model injection system for stagnation testing.

Aerothermal ground testing is essential for the successful development and demonstration of flexible thermal protection systems (FTPS) which must be evaluated over a range of flight relevant conditions. One commonly used type of facility, that produces flight relevant conditions of heat flux, surface pressure, and aerodynamic shear force, is the arc-jet facility. For this investigation the Boeing Large Core Arc Tunnel 
(LCAT), located in St. Louis, Missouri was employed. Test techniques have been developed for testing the FTPS article and acquiring the necessary data in the LCAT facility. ${ }^{1}$

The Boeing LCAT facility uses a Huels arc heater with air as the test gas and a pumped test cabin to provide the test conditions of interest. The LCAT arc-jet facility, shown in Fig. 1a, has multiple optical viewing ports in the test cabin, at various angles relative to the test model, to obtain video, still pictures, pyrometer, and infrared camera thermal data. A general overview of the LCAT facility along with performance envelopes for stagnation testing is presented in Ref. 4.
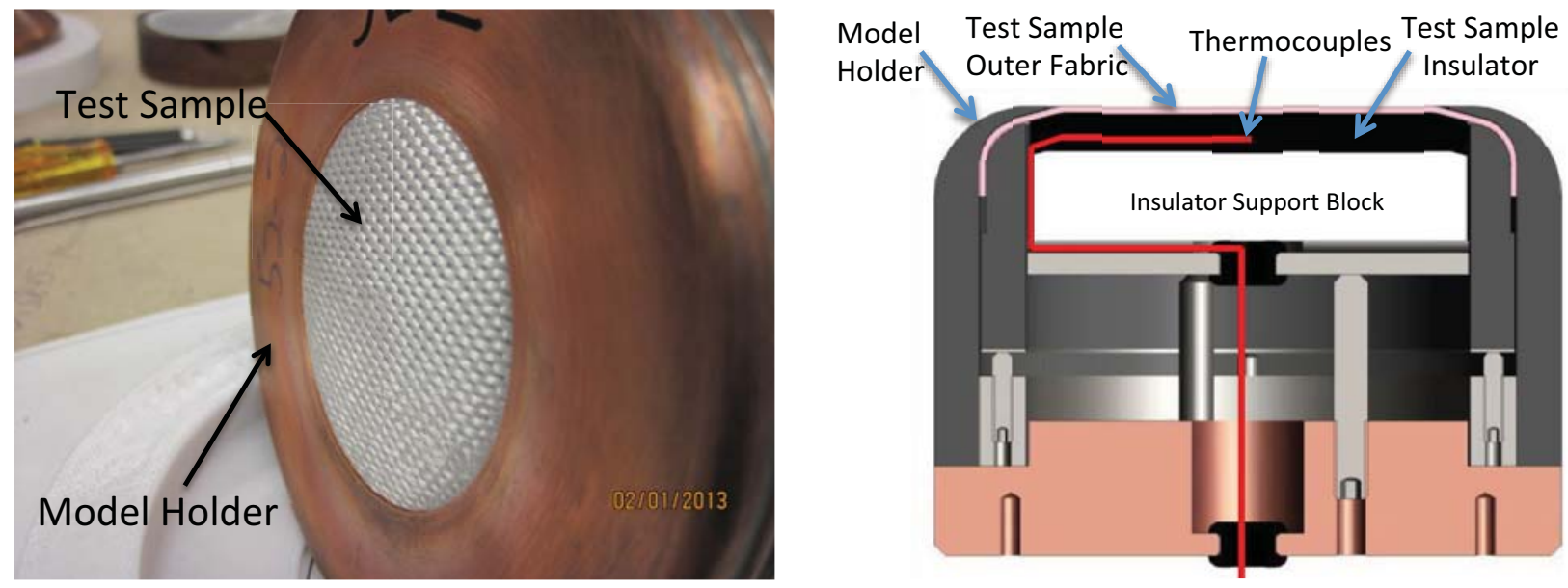

Figure 2. a) Face view of the stagnation, water-cooled model holder with a FTPS sample installed, and b) schematic of the sample holder geometry.

For stagnation testing, a $15.24 \mathrm{~cm}$ (6 in.) exit diameter, conical nozzle is used to provide the correct combination of heat flux and model surface pressure. The $11.43 \mathrm{~cm}$ (4.5 in.) diameter stagnation model is positioned on the centerline of the flow $22.86 \mathrm{~cm}$ (9 in.) downstream of the nozzle exit so that the model face can be seen through the viewing window shown in Fig. 1b. Note that a rotary arm was used in the arc-jet, therefore all measurements were conducted on the centerline. Two FTPS test specimens, supported by copper water cooled model holders (Fig. 2), and one calibration probe measuring stagnation point heat flux and pressure are injected into the test flow during each run. Figure 3 shows a stagnation test model in the arc-jet test flow. Note that the water cooled holder provides a cold-wall heat flux measurement.

A flat-face calibration probe is used to determine the flow-field stagnation heat flux and surface pressure during each run. The probe has a heat flux sensor and a pressure port on the flat face with the heat flux gage located at the center of the probe and the pressure port slightly off-center. In addition to measuring the flow-field properties, conditions in the arc heater are measured including the flow total pressure upstream of the nozzle throat, total air mass flow rate, and average flow enthalpy.

Because of the relatively small size of the arc-jet test article and the fact that the arc-jet test gas free stream velocity is relatively low compared to the free stream environment of the flight vehicle, the flow physics and chemistry surrounding the FTPS test sample are not directly representative of the flight environment. For this reason, a methodology

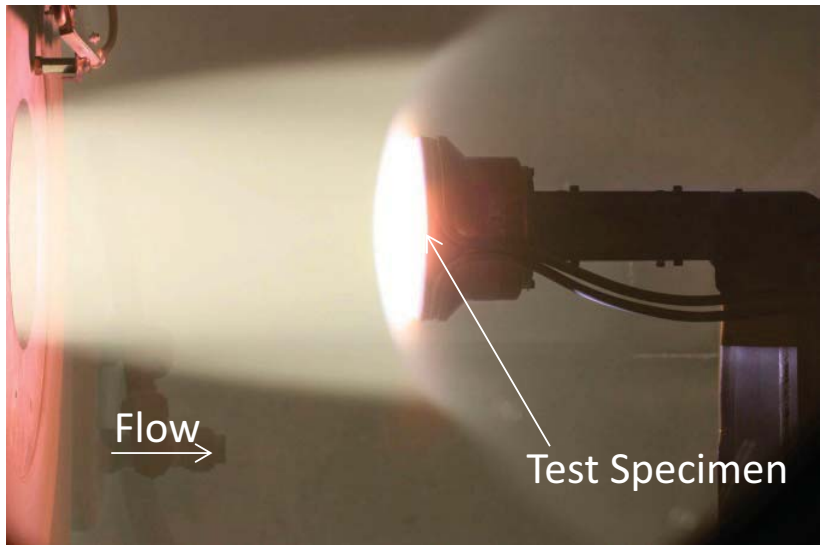

Figure 3. Side view of the stagnation test model in the arc-jet flow. is introduced, with the help of computational fluid dynamic simulations and equilibrium gas theory, to correlate the arc-jet conditions to the relevant flight environment. 


\section{Methodology: Arc-Jet free stream Condition Estimation}

In this section, a method to estimate flight-relevant arc-jet free stream condition is proposed. An iterative equilibrium theory loosely coupled with a non-equilibrium Computational Fluid Dynamics (CFD) process was developed to estimate the arc-jet free stream condition given the arc heater chamber pressure, bulk enthalpy, and calibrated surface heat flux and the pressure measured by the calibration probe. The proposed steps for the equilibrium process are schematically shown in Fig. 4. The non-equibrium process is discussed in the text. Equilibrium theory was used to estimate an initial condition for the non-equilibrium CFD, which was then used to verify and/or adjust the initial condition.

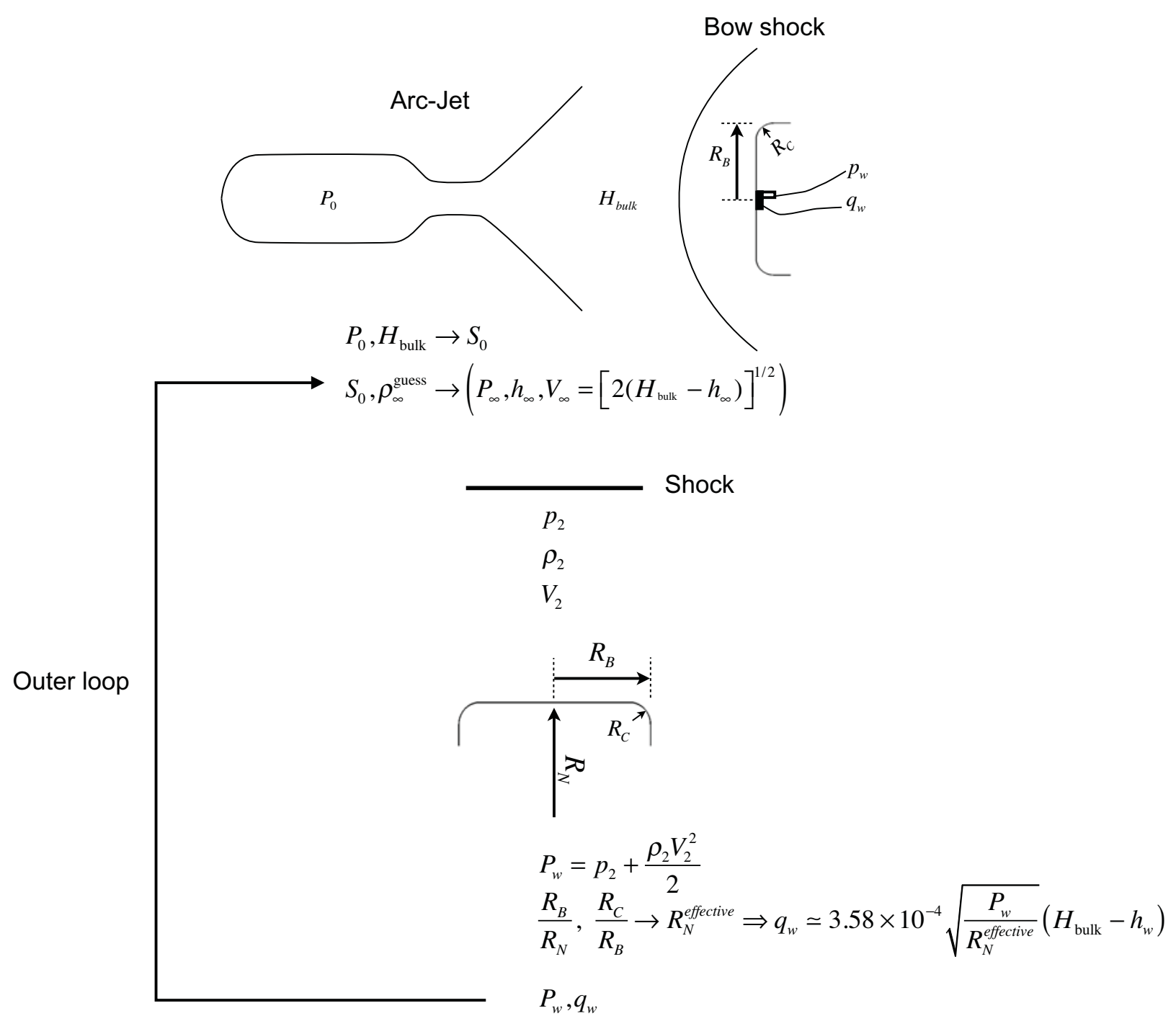

Figure 4. Methodology: Arc-jet schematic and equilibrium analysis process for the arc-jet free stream condition estimation. (Note: The non-equilibrium process is discussed in the text.)

In the equilibrium process, the arc-jet chamber pressure and the bulk enthalpy were used to estimate the gas entropy. (Note that the bulk enthalpy was measured based on the energy balance through the arc heater.) This bulk enthalpy was later compared with the inferred enthalpy which was computed from the surface heat flux and pressure. An isentropic expansion through the nozzle was assumed with an iterative scheme to estimate the free stream density that corresponds to the calibration probe surface pressure and heat flux. The stagnation heat flux was estimated using an engineering correlation that is a function of the 
sample holder stagnation curvature, its base and corner radii: ${ }^{5,6}$

$$
q_{w} \simeq 3.58^{-4} \sqrt{\frac{P_{w}}{R_{N}^{\text {effective }}}}\left(H_{\text {bulk }}-h_{w}\right)
$$

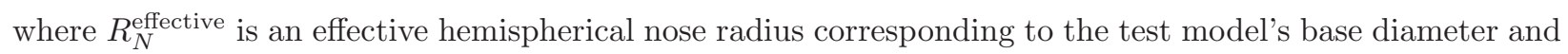
corner radius (Fig. 5.) A few examples in obtaining the effective radii that were relevant to this study are as follows (see Ref. 5):

$$
\frac{R_{B}}{R_{N}}=0, \frac{R_{C}}{R_{B}}=\left\{\begin{array}{l}
0.29\left(R_{B}=1.75 ", R_{C}=0.500 "\right) \\
0.06\left(R_{B}=2.25 ", R_{C}=0.125 "\right) \\
0.22\left(R_{B}=2.25 ", R_{C}=0.500 "\right) \\
0.05\left(R_{B}=2.50 ", R_{C}=0.125 "\right)
\end{array} \rightarrow \frac{q}{q_{\text {hemisphere }}}=\left\{\begin{array}{l}
0.59 \\
0.54 \\
0.57 \\
0.53
\end{array}\right.\right.
$$

where the effective radius is inversely proportional to the square of the non-dimentional heat flux of Eq. 2 through the following relation:

$$
R_{N}^{\text {effective }}=\frac{R_{B}}{\left(q / q_{\text {hemisphere }}\right)^{2}}
$$

The initial estimated free stream density along with the gas entropy were sufficient to estimate the gas thermodynamic properties needed for the non-equilibrium CFD computations.

The main purpose of this iterative process was to find ranges of the free stream density, that with the gas entropy, match the calibration probe surface values. The results of the equilibrium analysis were used as initial conditions for the non-equilibrium CFD computations. An example is presented in Fig. 6 showing the results of the described iterative process for an arc-jet bulk enthalpy and chamber pressure of $3.6 \mathrm{MJ} / \mathrm{kg}$ and $153 \mathrm{kpa}$, respectively. These conditions correspond to the calibrated arcjet conditions tested on a 3.5 inch diameter calibration probe with a 0.5 inch corner radius for a surface pressure and heat flux of about $3.3 \mathrm{kpa}$ and $20 \mathrm{~W} / \mathrm{cm}^{2}$, respectively. The shaded area shown in Fig. 6 refers to the range of possible free stream densities that could be used to match the calibration probe surface values. The width of the shaded area depends on the estimated arc-jet enthalpy and the calibration probe surface values. Figure 7 shows an example analyzed for an enthalpy and calibrated surface heat flux of about $6.9 \mathrm{MJ} / \mathrm{kg}$ and $60 \mathrm{~W} / \mathrm{cm}^{2}$, respectively. In this figure, the arc-jet calibrated values were for the 3.5 inch diameter calibration model, which had a corner radius of 0.5 inch. In addition, the predicted

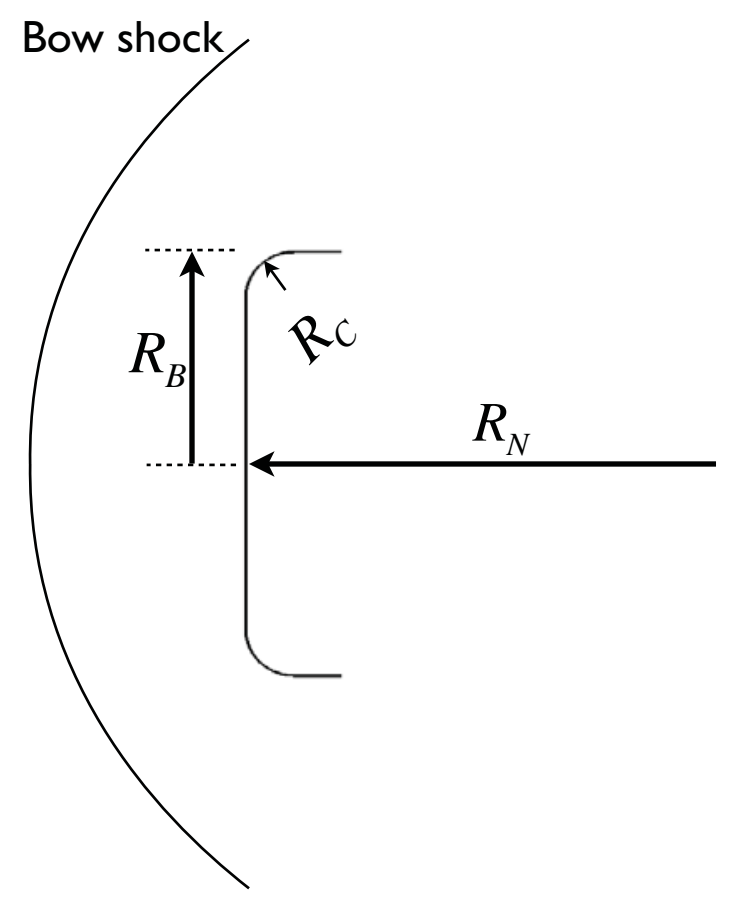

Figure 5. Schematic of the arc-jet calibration or the FTPS sample holder geometry. equilibrium theory for surface pressure and head flux and on different geometries are also shown in the same plot for comparison. As shown, the shaded area covers a wide range of free stream densities, meaning that the equilibrium theory was more inaccurate in the high enthalpy condition than the low enthalpy arc-jet conditions when estimating the arc-jet free stream values.

The initial condition was estimated by selecting a free stream density from the shaded area (e.g. see Fig. 6) along with the arc-jet enthalpy. This estimated initial free stream condition was then applied to the high-fidelity CFD simulations. In the CFD simulations, the free stream gas was modeled with an 11-species air $\left(\mathrm{N}_{2}, \mathrm{O}_{2}, \mathrm{NO}, \mathrm{N}, \mathrm{O}, \mathrm{N}_{2}^{+}, \mathrm{O}_{2}^{+}, \mathrm{NO}^{+}, \mathrm{N}^{+}, \mathrm{O}^{+}, \mathrm{e}^{-}\right)$. Thermal nonequilibrium was modeled by including both the translational and the vibrational energy equations in the simulations. Surface temperatures of the test samples were assumed to be in radiative equilibrium with a constant emissivity of 0.85 . 


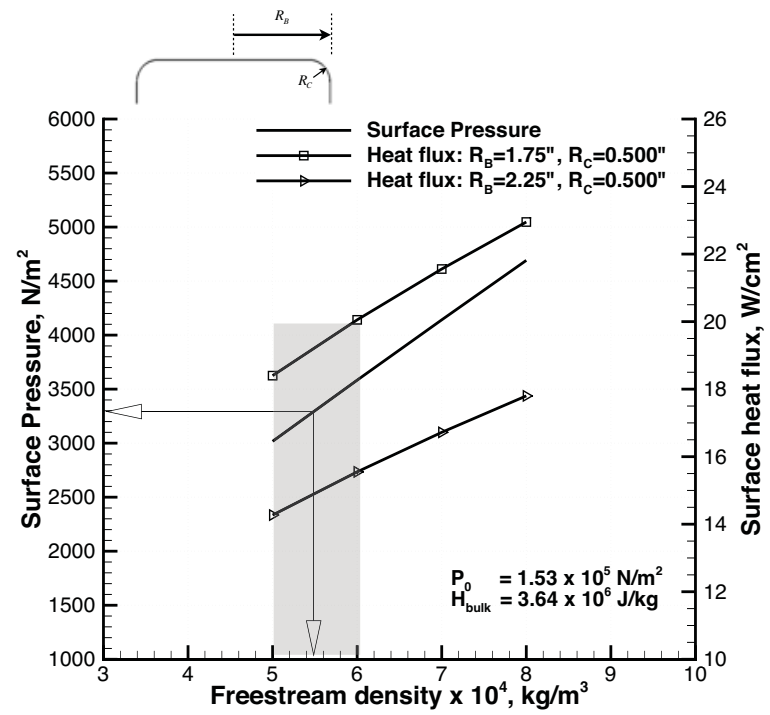

Figure 6. Initial free stream density corresponding with calibrated surface pressure and heat flux of $3.3 \mathrm{kpa}$ and $20 \mathrm{~W} / \mathrm{cm}^{2}$, respectively, for the 3.5 inch diameter sample holder with a 0.5 inch corner radius condition.

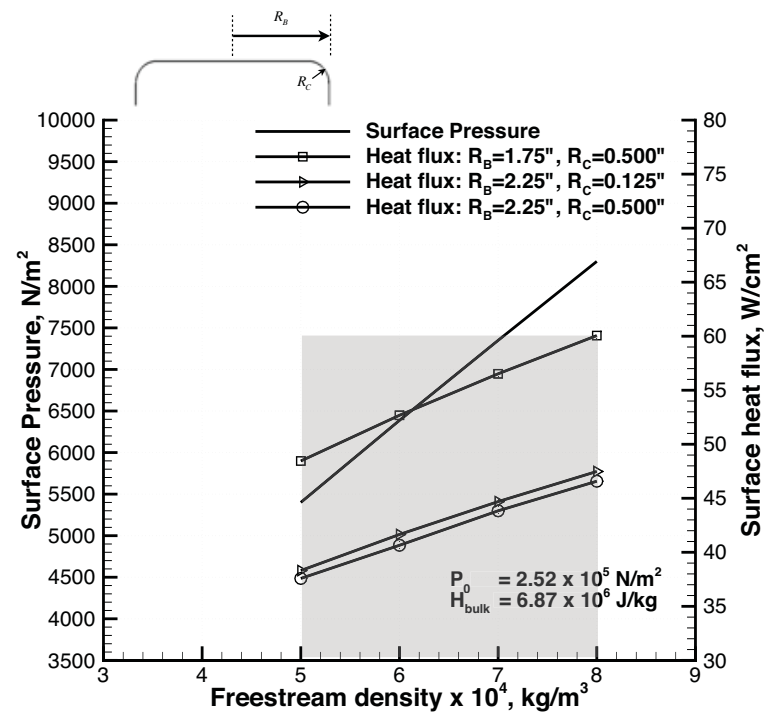

Figure 7. Initial free stream density corresponding with calibrated surface pressure and heat flux of $5.2 \mathrm{kpa}$ and $60 \mathrm{~W} / \mathrm{cm}^{2}$, respectively, for the 3.5 inch diameter sample holder with a 0.5 inch corner radius condition. 
For the flowfield environment, the transport and thermodynamic properties were computed from species collision integrals $^{7-9}$ and curve fit data, ${ }^{10}$ respectively. All fluid flow simulations were computed with the Langley Aerothermodynamic Upwind Relaxation Algorithm (LAURA)-5 code. ${ }^{11}$ LAURA-5 is a hypersonic viscous reacting flow solver that has been applied to analyze flight data in previous NASA missions, such as Fire II, ${ }^{12}$ the Space Shuttle Orbiter, ${ }^{13,14}$ and the Mars Science Laboratory (MSL), ${ }^{15}$ and is being used in current programs, such as the Multi-Purpose Crew Vehicle (MPCV), ${ }^{16}$ the Inflatable Reentry Vehicle Experiment-3 (IRVE-3), and the HEART vehicle. ${ }^{17}$

During the CFD process, the computational grid was adapted and refined around the bow shock (Fig. 8). The surface pressure and heat flux values predicted using the estimated initial conditions and the CFD code were then compared with the measured probe values. Necessary adjustments were made to the free stream conditions to match the calibrated values using the following relations:

$$
\begin{aligned}
q_{w} & \sim \sqrt{\rho_{\infty}} V_{\infty}^{3} \\
p_{w} & \sim \rho_{\infty} V_{\infty}^{2}
\end{aligned}
$$

This process was repeated several times until the predicted CFD values were within $5-10 \%$ of both calibration probe values.

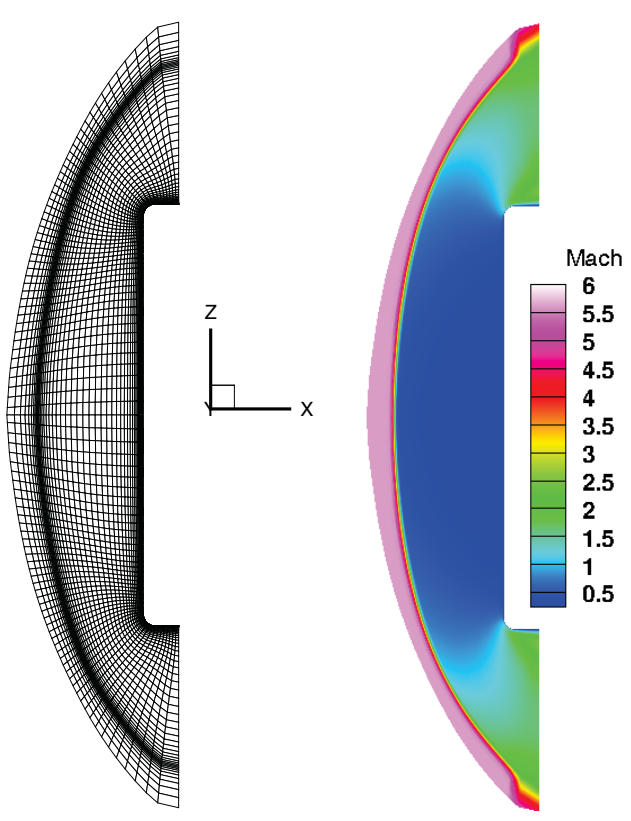

Figure 8. a) Computational grid after adaptation process, and b) the corresponding Mach contour plot.

\section{Arc-Jet Environment}

A series of simulations were performed to assess the estimated calibrated arc-jet environments for the Flexible Thermal Protection System (FTPS) that is proposed for the HEART vehicle. The FTPS test sample consisted of two layers of NeXtel-440, four layers of Pyrogel-2250, and a layer of Kapton Kevlor Laminate (KKL) as the thermal barrier (Ref. 18.) In all the simulations, the arc-jet free stream conditions were estimated with the process described in Section II. The arc-jet data were available only for the 3.5 inch diameter calibration probe with a 0.5 inch corner radius. To study the effects of the sample holder geometry on the FTPS surface heat flux and pressure variations, the 3.5 inch calibration data were used in the simulations for geometries with different dimensions. The sample holder geometry was made with copper and therefore it was assumed that the surface is more closely represented by the fully-catalytic condition. The surface catalytic condition of the FTPS test sample was not precisely known and therefore simulations were conducted for both fully- and non-catalytic conditions. The fully-catalytic surface has $100 \%$ efficiency in promoting species recombinations on the surface, while the non-catalytic surface does not allow species recombinations to take place on the surface.

Figure 9 shows predicted surface heat flux, shear, and pressure for the 3.5 inch diameter sample holder at different calibrated surface heat fluxes and pressures. The x-axis shows the distance ("Z") that was measured from the center to the edge of the sample. The plots on the left show the predicted values using the initial condition estimated from the equilibrium theory process described in Section II. The CFD results predicted using the final adjusted free stream conditions estimated iteratively using the non-equilibrium results are shown on the right. The inferred enthalpies corresponding to the adjusted free stream conditions were computed and shown with an added asterisk. The differences between the arc-jet estimated bulk enthalpy and computed inferred enthalpy were recorded as one of the uncertainties in Section VI. A summary of all the simulated results including the calculated uncertainties is tabulated in Table 1. The uncertainty for the enthalpy was increased with the increase of the calibration probe stagnation heat flux values. This is illustrated in Fig. 10. For the $77 \mathrm{~W} / \mathrm{cm}^{2}$ test condition, the arc-jet bulk enthalpy value was too low compared with the rest of the test conditions. A repeat of this test is recommended for further diagnostics.

The corresponding free stream conditions estimated from simulating the 3.5 inch diameter calibration probe were applied to the FTPS, which was mounted on sample holders with the same geometry as the 


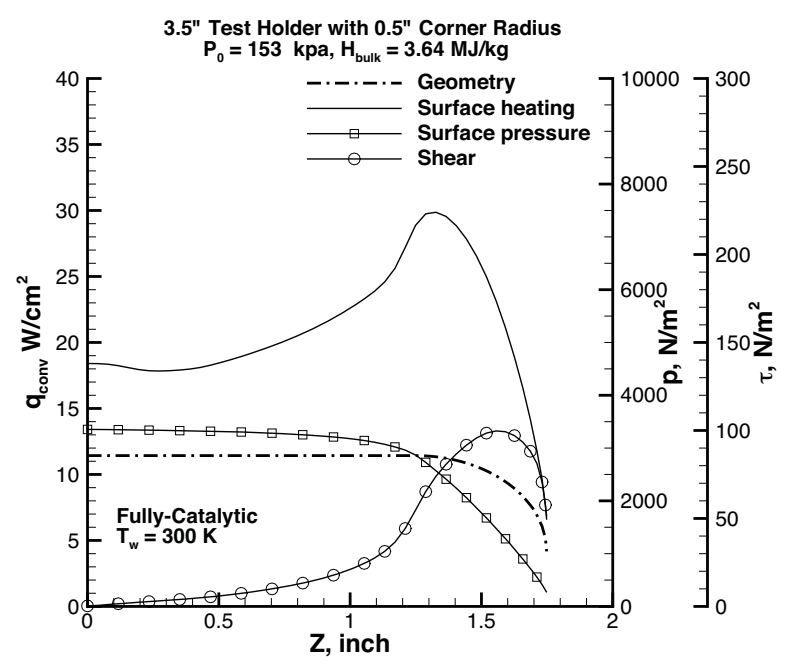

(a) $20 \mathrm{~W} / \mathrm{cm}^{2}, 3.0 \mathrm{kpa}$ : Using initial free stream

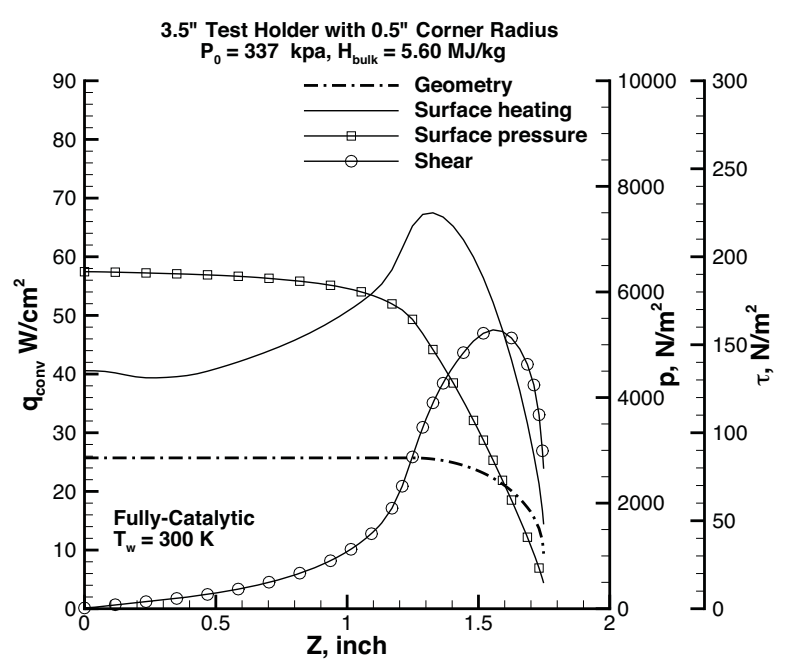

(c) $40 \mathrm{~W} / \mathrm{cm}^{2}, 6.6 \mathrm{kpa}$ : Using initial free stream

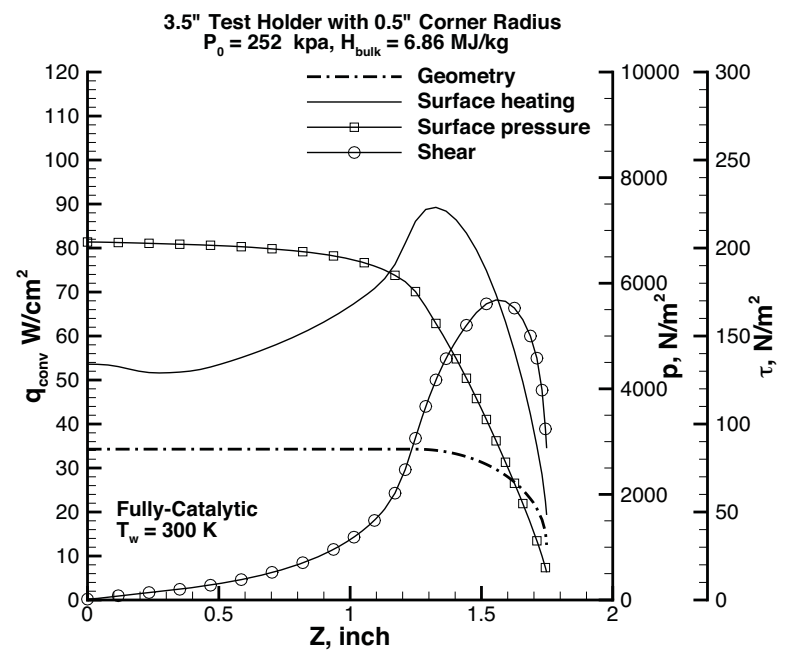

(e) $60 \mathrm{~W} / \mathrm{cm}^{2}, 5.2 \mathrm{kpa}$ : Using initial free stream

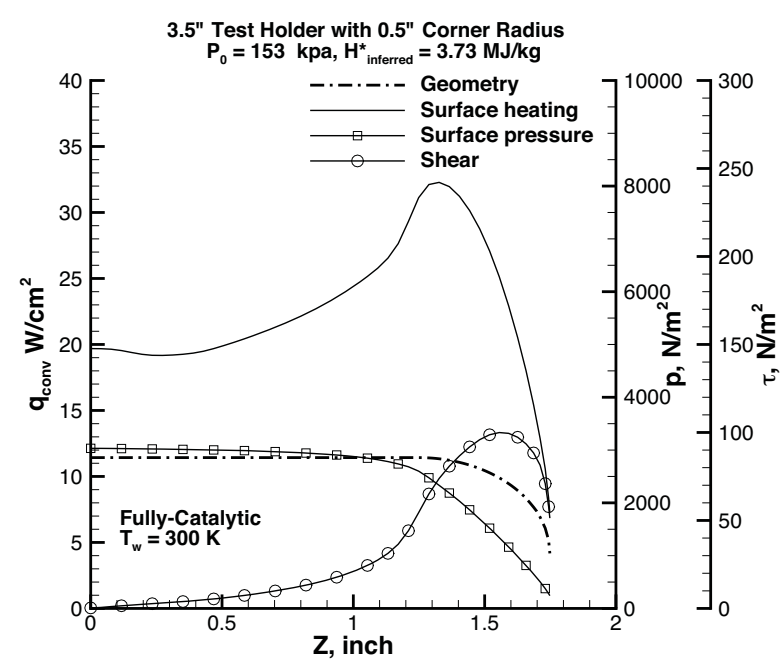

(b) $20 \mathrm{~W} / \mathrm{cm}^{2}, 3.0 \mathrm{kpa}$ : Using adjusted free stream

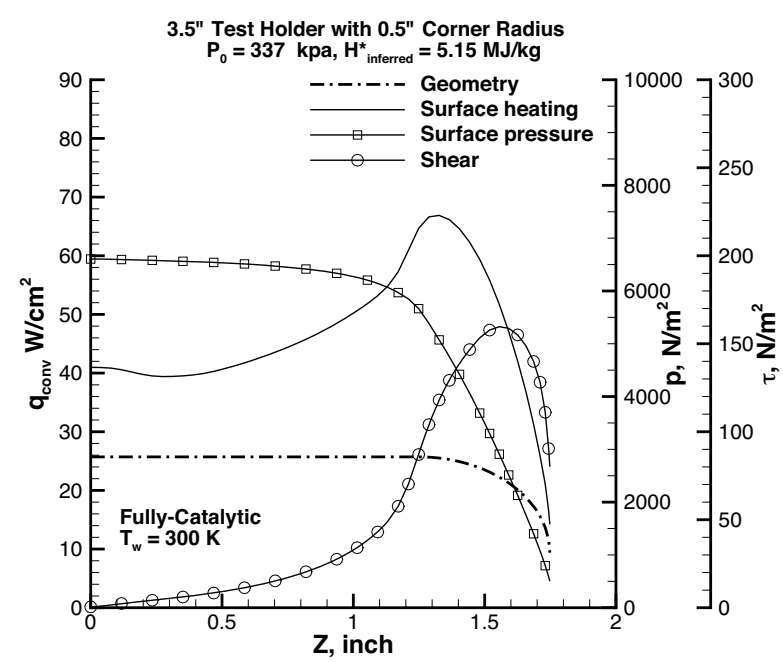

(d) $40 \mathrm{~W} / \mathrm{cm}^{2}, 6.6 \mathrm{kpa}$ : Using adjusted free stream

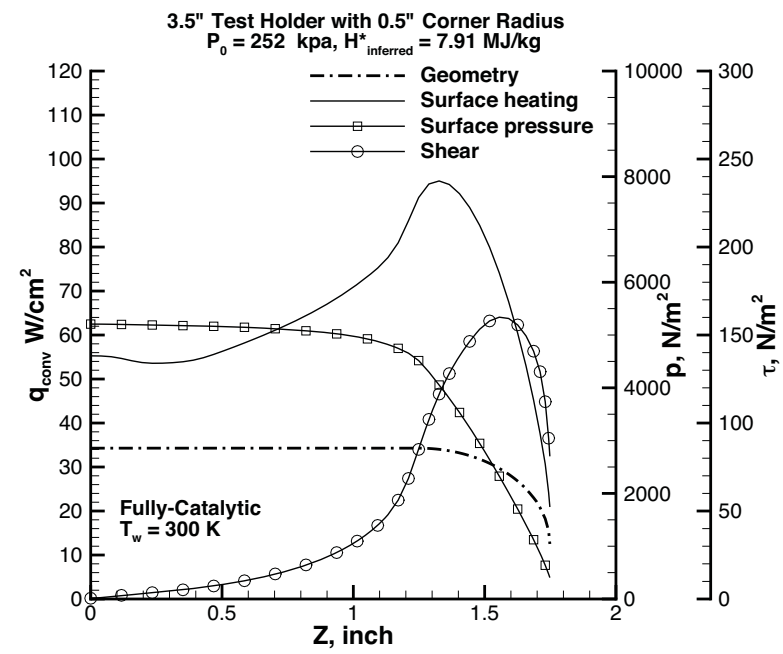

(f) $60 \mathrm{~W} / \mathrm{cm}^{2}, 5.2 \mathrm{kpa}$ : Using adjusted free stream

Figure 9. Computational results for different arc-jet conditions for the 3.5 inch diameter sample holder with a 0.5 inch corner radius. 


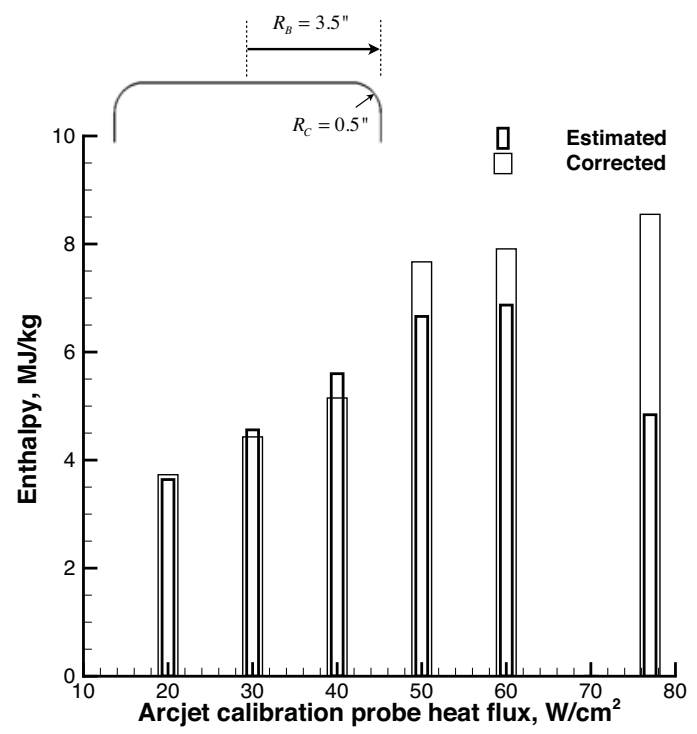

Figure 10. Comparison between the arc-jet estimated and corrected (computed) inferred enthalpy for different calibrated conditions.

calibration probe. Various geometrical dimensions were used to study their effects on surface heat flux and pressure profiles. Catalytic surface effects on surface heat flux were also studied.
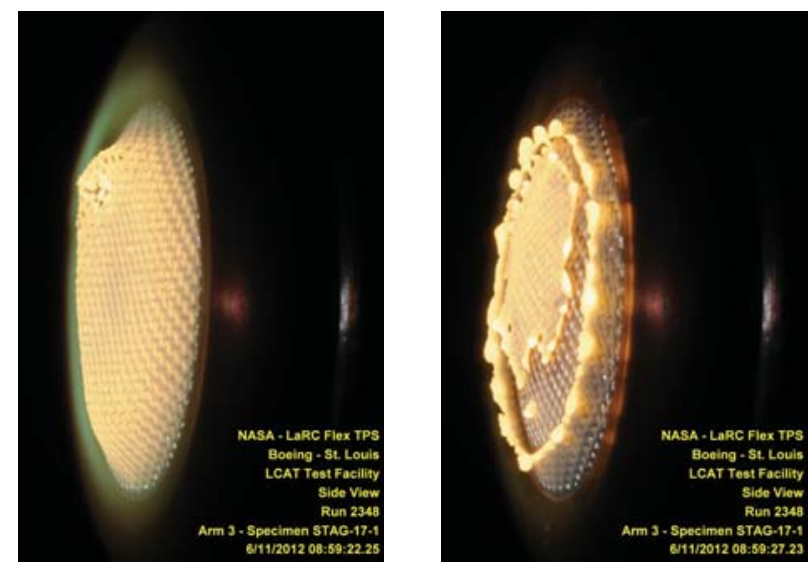

Figure 11. Result of an arc-jet test conducted on a FTPS mounted on the 3.5 inch diameter sample holder with a 0.5 inch corner radius at $40 \mathrm{~W} / \mathrm{cm}^{2}$.

The simulations were also used to assess the effects of the FTPS sample holder geometry on the surface heat flux and pressure for the 2 inch exposed area of the FTPS test sample. The main purpose for evaluating the effects of the model holder dimensions on surface heat flux and pressure profiles was to achieve both a flatter surface heat flux and pressure profile across the FTPS test sample. Earlier arc-jet tests indicated that the FTPS were failing due to high surface heat flux and shear values on the outer diameter of the FTPS sample that caused the outer layer fabric to bulge and consequently melt at the outer diameter (see Fig. 11.) Since the calibration probe measured the surface pressure and heat flux at the center of the sample, and this was the location the arc-jet was adjusted to match, the outer diameter of the sample consequently experienced an over-test condition with higher heat flux and surface shear conditions than desired.

A series of arc-jet tests were conducted and it was determined that the maximum sample holder diameter that can be used in the LCAT facility without a major tunnel blockage that could possibly affect the test results is about $4.5 \mathrm{inch}$. No apparent limitation on the corner radii was observed. Thus, a series of analyses on different sample holder geometries up to 4.5 inch in diameter were performed to recommend a sample holder geometry that produced flatter surface heat flux and pressure across the FTPS fabric. 


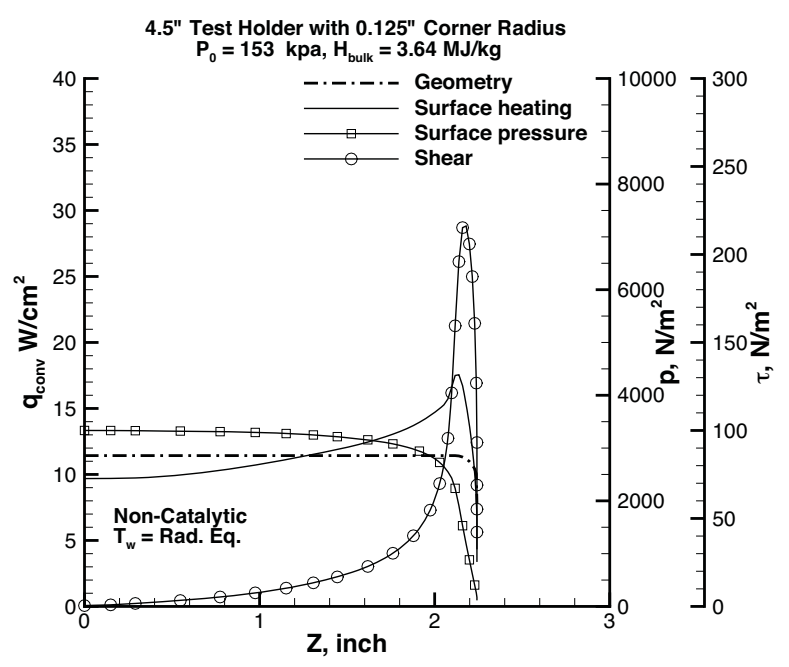

(a) $20 \mathrm{~W} / \mathrm{cm}^{2}$, Non-Catalytic

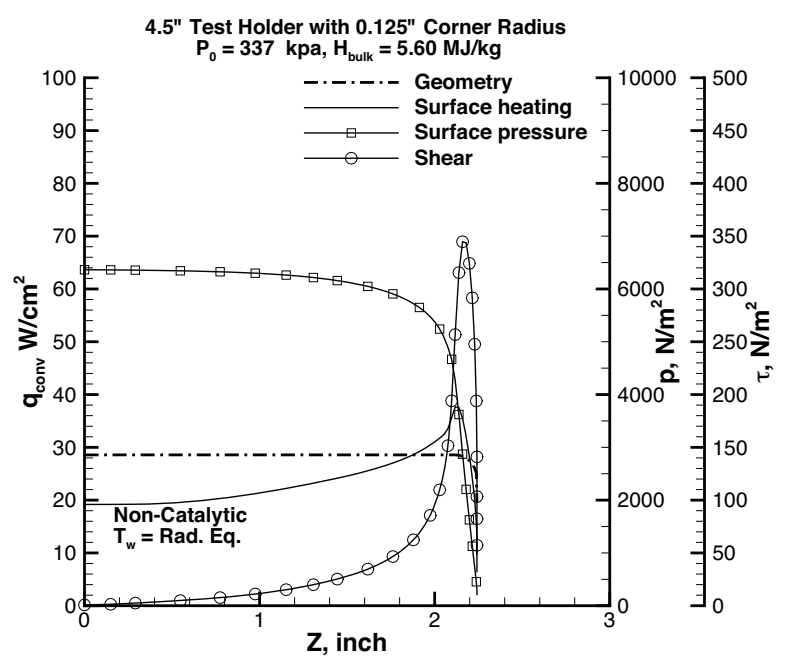

(c) $40 \mathrm{~W} / \mathrm{cm}^{2}$, Non-Catalytic

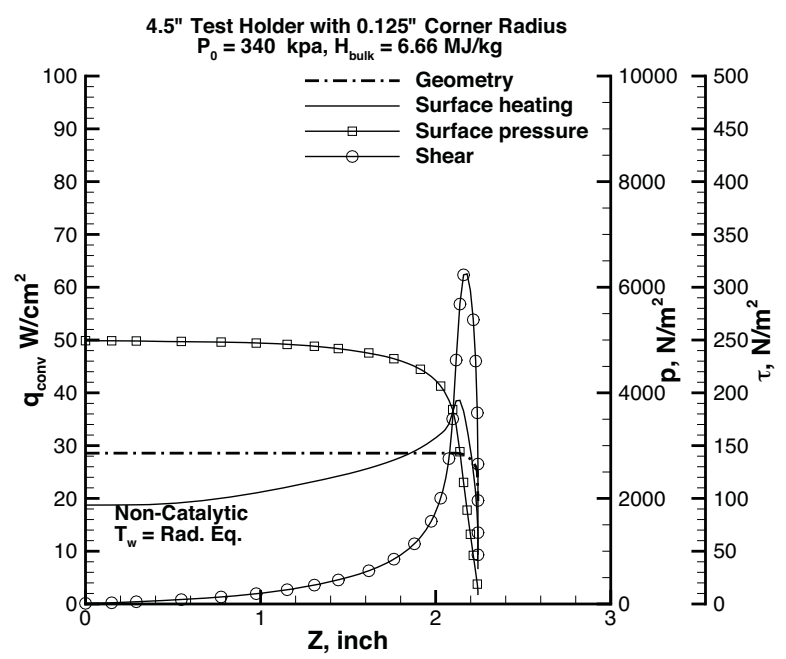

(e) $50 \mathrm{~W} / \mathrm{cm}^{2}$, Non-Catalytic

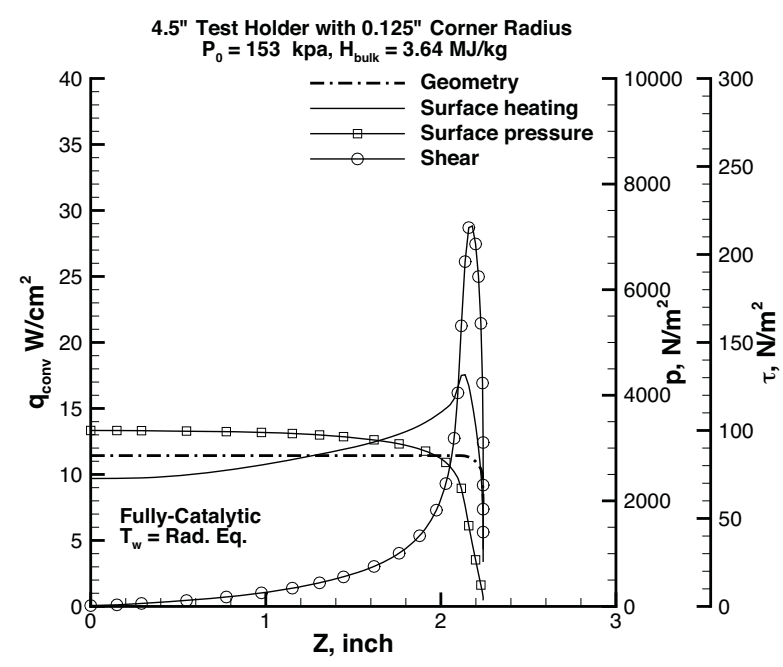

(b) $20 \mathrm{~W} / \mathrm{cm}^{2}$, Fully-Catalytic

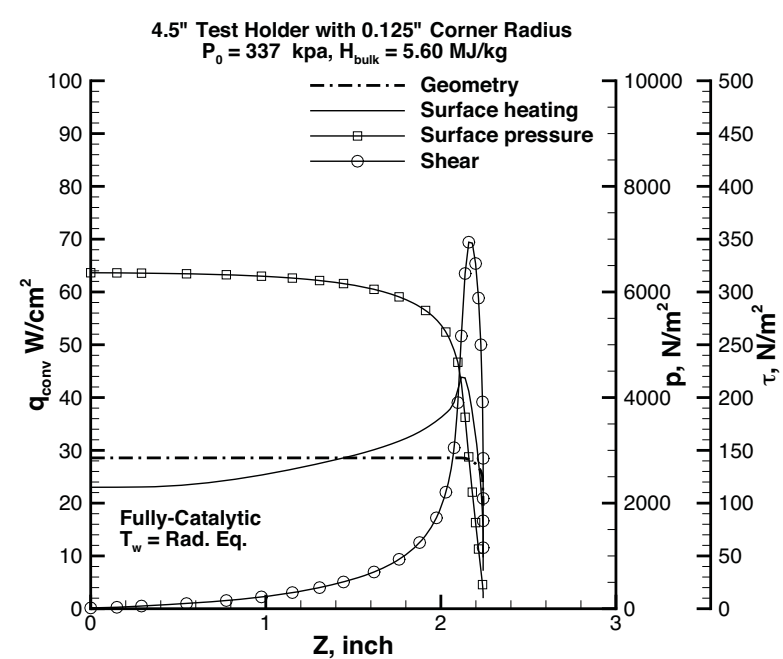

(d) $40 \mathrm{~W} / \mathrm{cm}^{2}$, Fully-Catalytic

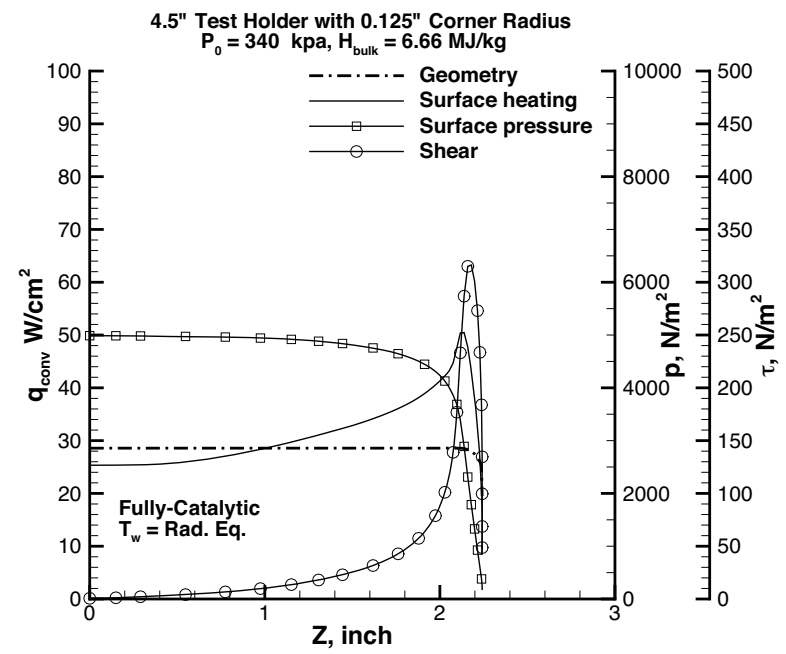

(f) $50 \mathrm{~W} / \mathrm{cm}^{2}$, Fully-Catalytic

Figure 12. Computational results for arc-jet conditions tested on the FTPS mounted on a 4.5 inch diameter sample holder with a 0.125 inch corner radius.

10 of 17 
Table 1. Summary of the computational results for different arc-jet conditions on the 3.5 inch diameter sample holder with a 0.5 inch corner radius.

\begin{tabular}{|c|c|c|c|c|c|}
\hline $\begin{array}{l}\mathrm{H}_{\text {bulk }} \\
\mathrm{MJ} / \mathrm{kg}\end{array}$ & \multicolumn{2}{|c|}{$\begin{array}{l}\text { Stagnation heat flux } \\
\qquad \mathrm{W} / \mathrm{cm}^{2}\end{array}$} & \multicolumn{2}{|c|}{$\begin{array}{c}\text { Stagnation surface pressure } \\
\text { kpa }\end{array}$} & $\begin{array}{c}\left(\mathrm{H}_{\text {inferred }}-\mathrm{H}_{\text {bulk }}\right) / \mathrm{H}_{\text {bulk }} \\
\%\end{array}$ \\
\hline & Calibration Probe & Computed & Calibration Probe & Computed & \\
\hline 3.64 & 20 & 19.69 & 3.03 & 3.03 & +2.5 \\
\hline 4.56 & 30 & 29.77 & 4.76 & 4.72 & -2.8 \\
\hline 5.60 & 40 & 40.97 & 6.60 & 6.60 & -8.0 \\
\hline 6.66 & 50 & 46.57 & 4.00 & 3.99 & +15.2 \\
\hline 6.87 & 60 & 55.27 & 5.24 & 5.02 & +15.1 \\
\hline 4.84 & 77 & 66.20 & 6.83 & 6.81 & +76.6 \\
\hline
\end{tabular}

The computational results for the FTPS on a 4.5 inch diameter sample holder with a 0.125 inch corner radius are presented in Fig. 12 for both nonand fully-catalytic conditions.

The differences between the results of non- and fully-catalytic conditions increased as the arc-jet calibrated stagnation heat flux increased. For example, the surface heat flux profile was relatively insensitive to the surface catalytic condition for the $20 \mathrm{~W} / \mathrm{cm}^{2}$ case while the catalytic effect was significant for the $50 \mathrm{~W} / \mathrm{cm}^{2}$ condition. However, both surface heat flux and pressure profiles were much flatter regardless of the surface catalytic condition compared to the 3.5 inch sample holder results shown previously in Fig. 9. Note that only a portion of the sample holder surface (central 2 inch diameter) was covered with FTPS (see Fig. 13) and therefore only the performance of these geometries on that region was of interest.

To better assess the effects of the sample holder

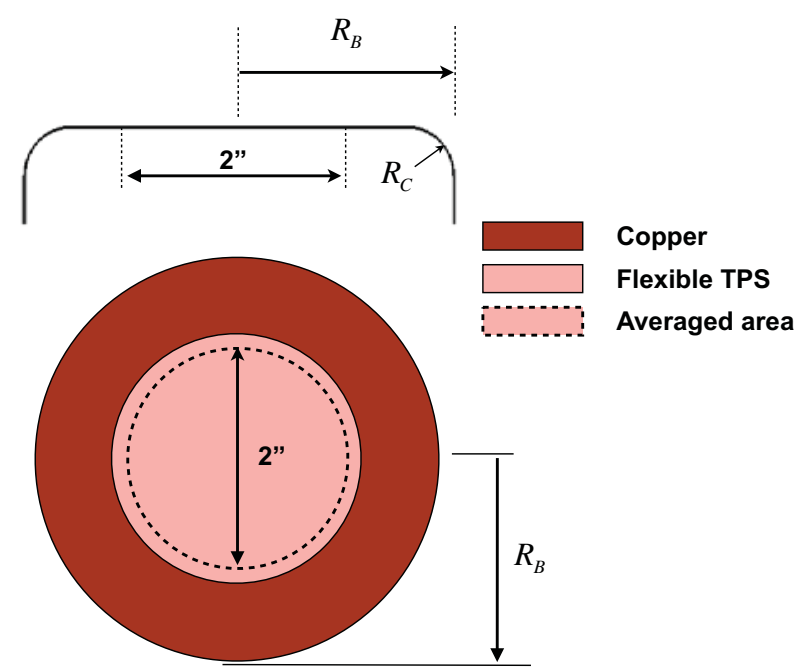

Figure 13. Schematic of the sample holder geometry and the averaged FTPS area. geometries on the surface heat flux variations across the FTPS, the heat flux at the edge of the FTPS (radius equals 1 inch) was compared with the corresponding stagnation point value using the following equation:

$$
\text { Heat flux variation }=\frac{q_{1} \text { " from stagnation }-q_{\text {stagnation }}}{\bar{q}} \times 100
$$

where $\bar{q}$ is the area weighted averaged surface heat flux which is defined as

$$
\bar{q}=\frac{\int q \cdot A d A}{\int A d A}
$$

The results computed using Eq. 5 were compiled in graphical form and are presented in Fig. 14 for the 3.5 inch and 4.5 inch diameter sample holders with 0.5 inch corner radii and the 4.5 inch sample holder with a 0.125 inch corner radius. For the 3.5 inch diameter sample holder with a 0.5 inch corner radius, the heat flux variation on the FTPS was about $15-30 \%$. Increasing the diameter to 4.5 inch reduced the heat flux variation to $5-20 \%$ with the most significant decrease in the $40 \mathrm{~W} / \mathrm{cm}^{2}$ case. This is because the 4.5 inch sample holder with a 0.5 inch corner radius was closely representing an iso-heat flux geometry for the 40 $\mathrm{W} / \mathrm{cm}^{2}$ condition. However, reducing the corner radius to 0.125 inch on the 4.5 inch diameter sample holder provided a more uniform heat flux profile across a wide range of the conditions. Therefore, this geometry was recommended for the future FTPS stagnation testings. 


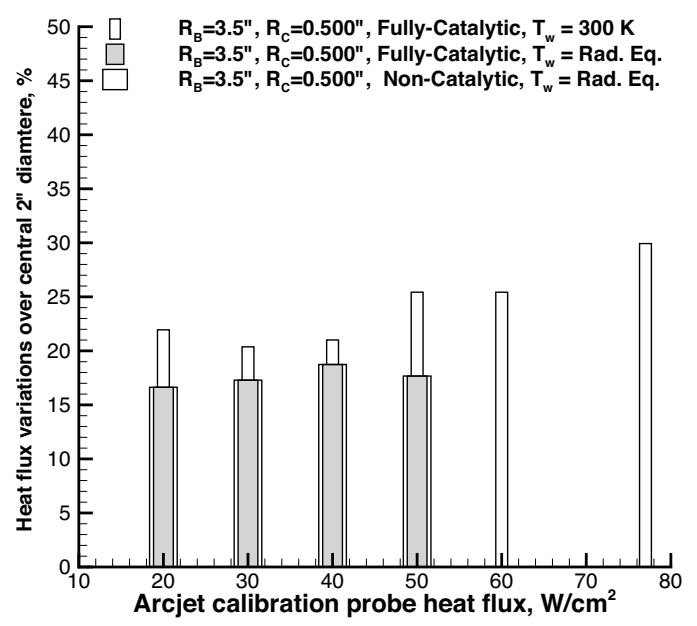

(a) 3.5 inch diameter sample holder with a 0.5 inch corner radius

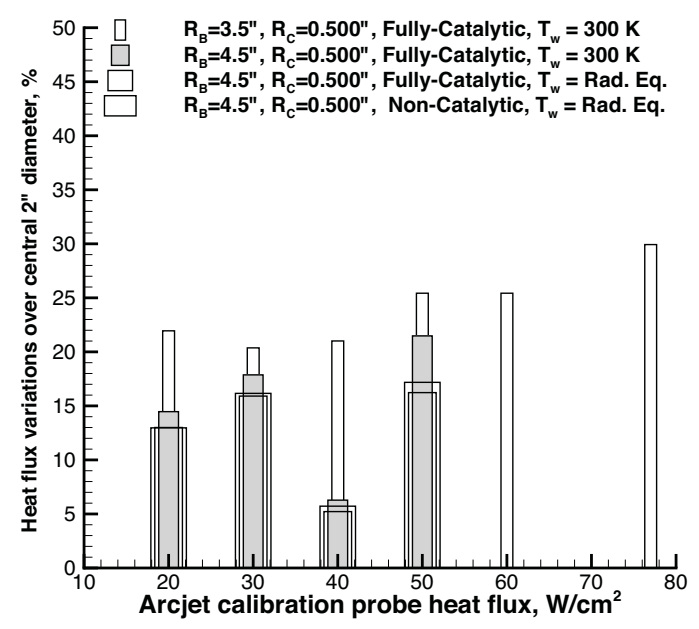

(b) 4.5 inch diameter sample holder with a 0.5 inch corner radius

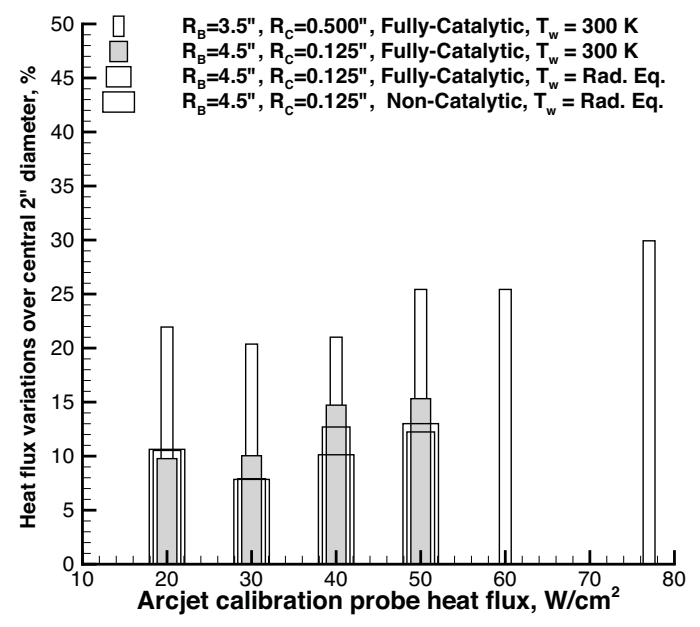

(c) 4.5 inch diameter sample holder with a 0.125 inch corner radius

Figure 14. Heat flux variation over central 2 inch area of the FTPS at different arc-jet conditions. 


\section{Flight Aeroheating Environment}

The flight aeroheating environments were needed to properly define the arc-jet flight-relevant conditions for the FTPS testing. This step was the last step prior to constructing correlation parameters to directly trace flight variables to the arc-jet variables. The HEART Type 12 outer mold line (OML) geometry (see Ref. 17) was considered for this process but the same process is applicable to other geometries of interest. HEART is a planned demonstration vehicle using a large inflatable, flexible TPS to reenter the Earth's atmosphere from the International Space Station (ISS). The HEART nominal and 3sigma high heat rate trajectories with and without cargo loads are shown in Fig. 15. The HEART flight aeroheating indicators were computed by simulating the actual HEART geometry at selected trajectory points shown in Fig. 15 as well as the HEART effective sphere geometry for every two seconds of the trajectory. All the flight CFD were performed with laminar, 5-species air $\left(\mathrm{N}_{2}, \mathrm{O}_{2}, \mathrm{NO}, \mathrm{N}, \mathrm{O}\right)$ and thermal equilibrium condition (one-temperature). The vehicle surface was assumed to be in radiative equilibrium with a constant emissivity value of 0.85 .

Figure 16 shows the HEART Type 12 OML flight aeroheating indicators for the nominal and 3-sigma high heat rate trajectories. In this figure, the symbols refer to the computational results performed on the HEART Type 12 geometry, while the solid lines refer to the computational results conducted on a sphere geometry with the effective radius corresponding to the HEART Type 12 geometry at the stagnation point. The effective radius for the HEART stagnation point was estimated to be about $2.6 \mathrm{~m}$.

Adjustments were made to the ballistic entry indicators due to the assumed $\pm 10^{\circ}$ angle of attack excursion. The effects of the angle of attack excursion to the aeroheating indicators were computed by comparing the ballistic entry results with the CFD computations performed on the three-dimensional

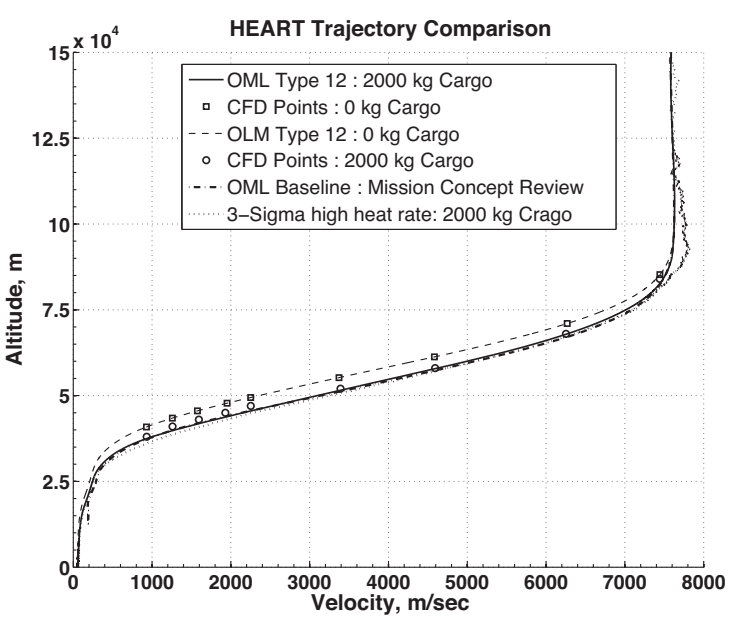

Figure 15. HEART trajectories with maximum and minimum cargo loads.

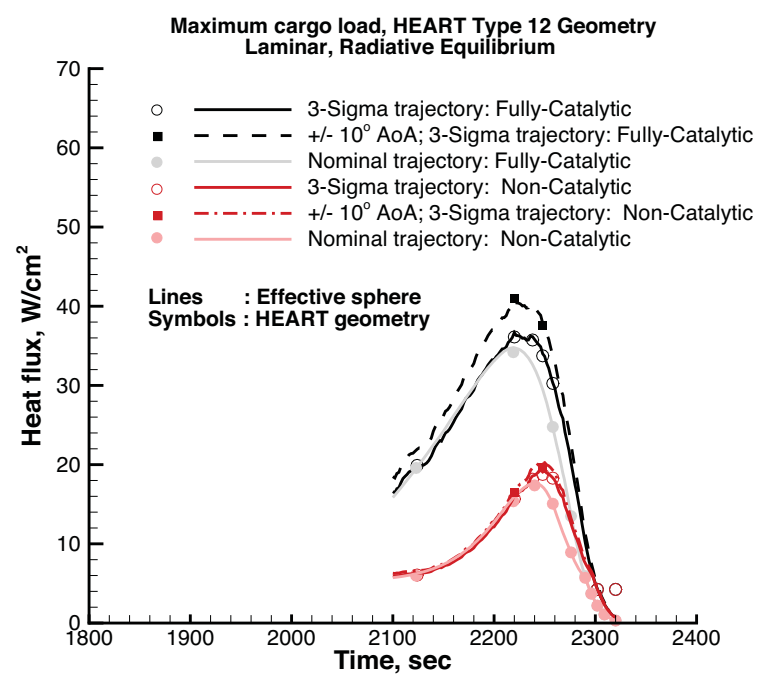

Figure 16. HEART Type 12 flight aeroheating indicator envelope.

HEART geometry with a $10^{\circ}$ angle of attack at two trajectory times for both catalytic surface conditions. According to the analysis it was predicted that the $\pm 10^{\circ}$ angle of attack variations from the ballistic entry affects the non- and fully-catalytic aeroheating environments by about $5.5 \%$ and $11.4 \%$, respectively. The adjusted indicators are shown in Fig. 16 with dashed lines. These adjusted aeroheating indicators were used in the flight-to-ground correlations discussed in Section VI.

The computed flight aeroheating indicators were curve fitted to a simple equation in the following form:

$$
q_{\text {Flight }}=C_{\alpha} C_{1} \rho_{\infty}^{m} V_{\infty}^{n}
$$

The coefficients of Eq. 7 are listed in Table 2 for non- and fully-catalytic surface conditions. In this table, separate coefficients are also provided for the Inflatable Aerodynamic Decelerator (IAD). The IAD coefficients exclude the rigid nose. 
Table 2. Flight aeroheating indicator coefficients for Eq. 7.

\begin{tabular}{llccccc}
\hline Body & Catalytic condition & \multicolumn{2}{c}{$C_{\alpha}$} & $C_{1}$ & $\mathrm{~m}$ & $\mathrm{n}$ \\
\cline { 3 - 4 } & & $\alpha= \pm 10^{\circ}$ & $\alpha=0^{\circ}$ & & & \\
\hline Nose+IAD & Fully-Catalytic & 1.114 & 1.0 & $2.11 \times 10^{-5}$ & 0.484 & 3.194 \\
Nose+IAD & Non-Catalytic & 1.055 & 1.0 & $3.70 \times 10^{-5}$ & 0.707 & 3.282 \\
IAD & Fully-Catalytic & 1.114 & 1.0 & $4.14 \times 10^{-6}$ & 0.513 & 3.401
\end{tabular}

Note that the first coefficient $C_{\alpha}$ is 1.0 unless the entry angle is other than ballistic. Comparisons between the aeroheating environment predicted by Eq. 7 and computed using CFD are shown in Fig. 17. Because the provided curve fit for non-catalytic surface was not completely following the computational predictions, the given curve fit is more suitable for the prediction of the aeroheating environment of the vehicle with a fullycatalytic surface condition than the noncatalytic surface. However, this form of the curve fit may be used for the aeroheating database generation and for design purposes, regardless of the surface catalytic condition. The computed curve fit was used in correlating the flight aeroheatong environment to the ground arcjet environment discussed next in Section VI.

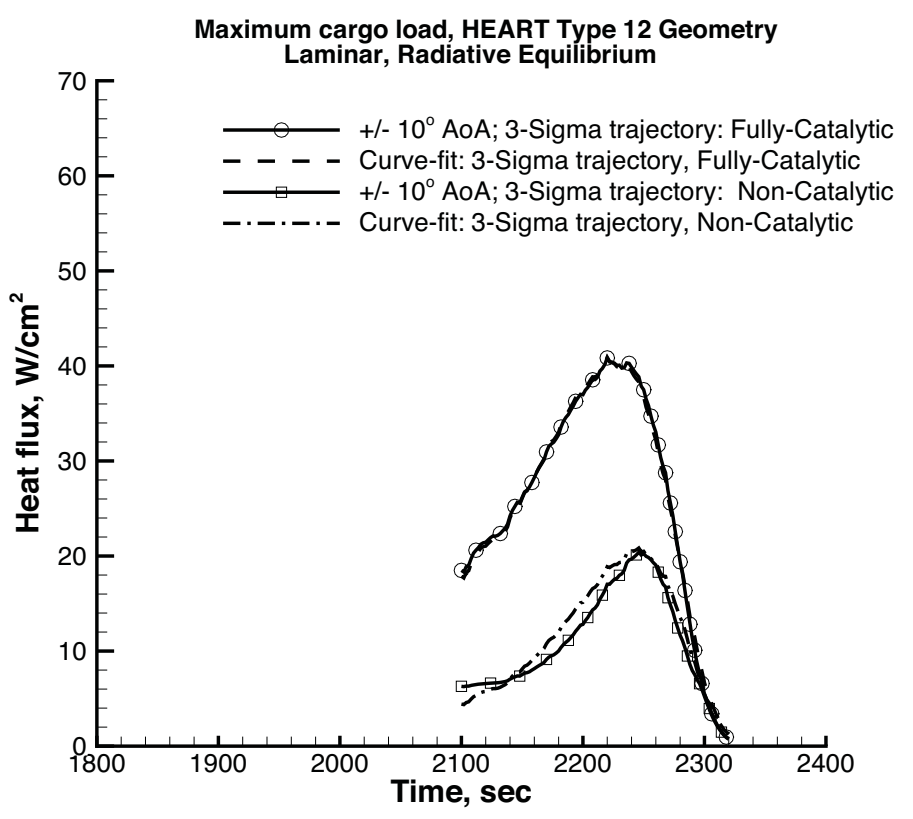

\section{Flight to Ground Correlations}

Figure 17. Comparison between the computed aeroheating data with the aeroheating curvefit equation.

The arc-jet data presented in Section IV were collected and arranged in the form of the arc-jet bulk enthalpy and the calibration probe surface heat flux. The differences between the predicted and the calibrated and/or estimated arc-jet values were added to the computational results as an uncertainty. The computed results were then separated based on the catalytic surface conditions considered in the computations. These results are shown in Fig. 18 for the lower and the upper bounds of the surface catalytic conditions. In this plot, the data are presented in the form of a ratio of the calibration probe heat flux measured with the water cooled probe (cold wall heat flux) to the heat flux the FTPS would experience under a calibrated arc-jet condition (hot wall heat flux). Accordingly, this ratio was decreased for the low enthalpy conditions, and then increased for higher enthalpy with non-catalytic FTPS. The same trend was observed for fully-catalytic FTPS when the uncertainty of the data was included in the analysis. The data trends were more clearly observed when the data were curve fit as shown in Fig. 18 with solid lines, for which the computed data uncertainties were included.

The arc-jet calibration probe surface heat flux variations with the arc-jet bulk enthalpy are presented in Fig. 19 for the HEART flight relevant heat flux values corresponding to non- and fully-catalytic surface conditions. The results showed that for the bulk enthalpy of up to $8 \mathrm{MJ} / \mathrm{kg}$, the calibration probe heat flux that needs to be tuned increases with the increase of the bulk enthalpy if the FTPS is non-catalytic. However, for fully-catalytic FTPS, this trend was reversed; meaning that the gap between the flight and the arc-jet calibration probe heat flux values decrease with an increase of the bulk enthalpy. Based on the 


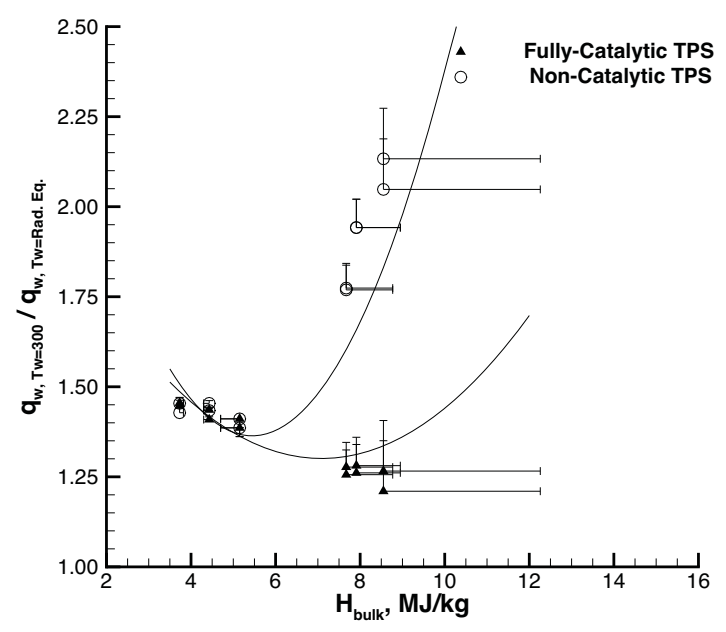

Figure 18. Trends of the calibrated arc-jet heat flux with the arc-jet estimated inferred enthalpy.

uncertainty of the measured and the computed data, it appeared that the non- and fully-catalytic data trends were similar for the bulk enthalpies higher than $8 \mathrm{MJ} / \mathrm{kg}$.

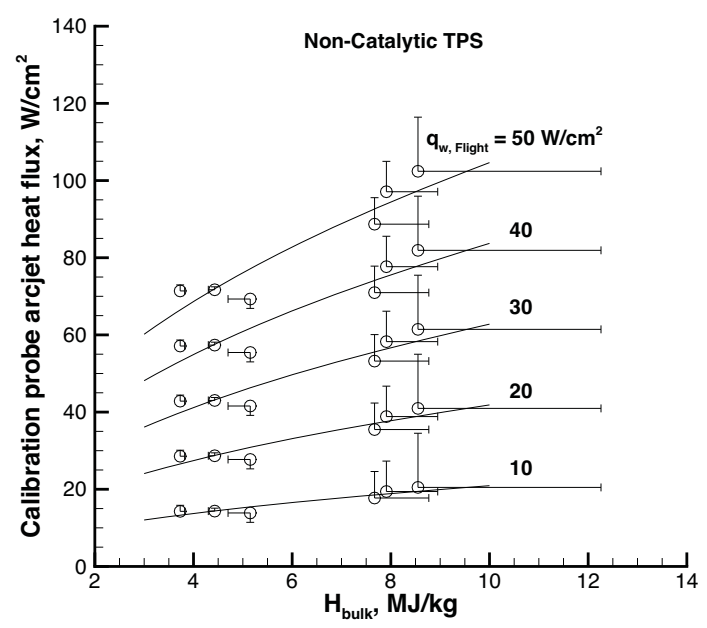

(a) Non-Catalytic TPS

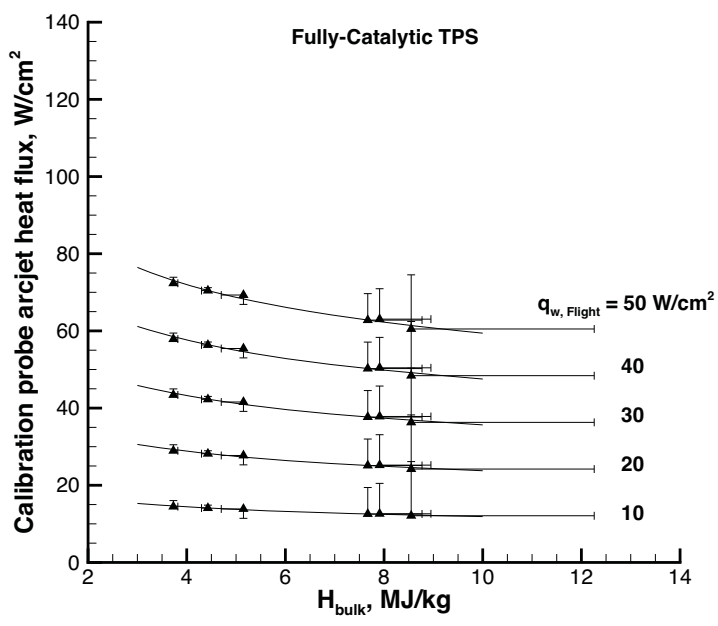

(b) Fully-Catalytic TPS

Figure 19. Trends of the calibration probe arc-jet heat flux with the arc-jet estimated bulk enthalpy.

The arc-jet and the flight data discussed in Sections IV and V, respectively, were correlated to the arc-jet bulk enthalpy and the flight aeroheating environment with a quadratic equation as:

$$
q_{\text {Arc-Jet }}=\left(A_{0}+A_{1} H_{\text {bulk }}+A_{2} H_{\text {bulk }}^{2}\right) q_{\text {Flight }}
$$

where $H_{\text {bulk }}$ is the arc-jet bulk enthalpy in $\mathrm{MJ} / \mathrm{kg}$, and $q_{\text {Flight }}$ is the flight heat flux defined by Eq. 7 . The coefficients of Eq. 8 are given in Table 3.

With the use of the flight to arc-jet correlation, the HEART specific arc-jet aerothermodynamic environments were plotted in Fig. 20 for the corresponding HEART 3-sigma high heat rate trajectory with a maximum cargo load of $2000 \mathrm{~kg}$. The horizontal axis represents the HEART entry time. The solid lines in this figure represent the HEART arc-jet indicators for a given arc-jet inferred enthalpy. The dashed lines are the surface pressure. These results suggest that the for non-catalytic FTPS samples compared with the 
Table 3. Arc-Jet calibration probe fight relevant heat flux indicator coefficients for Eq. 8.

\begin{tabular}{lccc}
\hline Catalytic condition & $A_{0}$ & $A_{1}$ & $A_{2}$ \\
\hline Fully-Catalytic & 2.13 & -0.233 & 0.0165 \\
Non-Catalytic & 2.81 & -0.532 & 0.0488
\end{tabular}

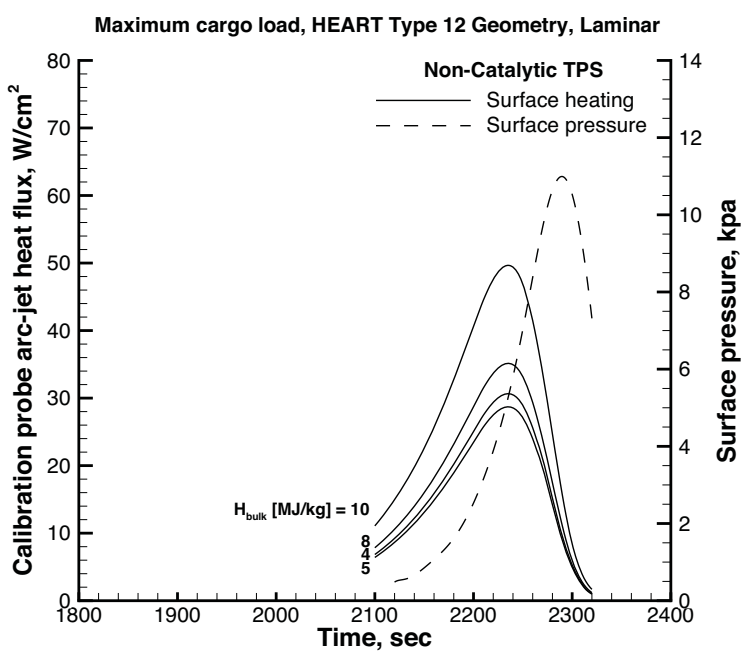

(a) Non-Catalytic TPS

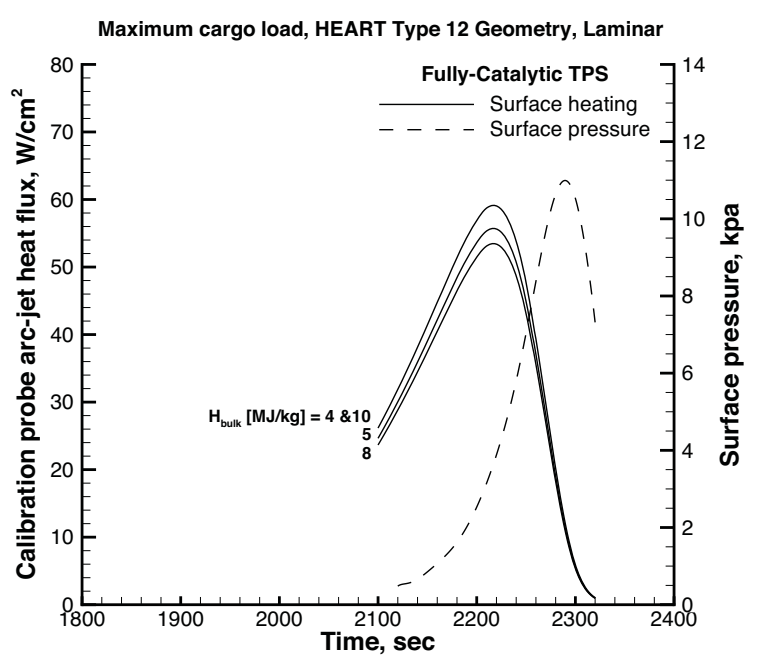

(b) Fully-Catalytic TPS

Figure 20. HEART arc-jet aeroheating environment.

fully-catalytic samples the arc-jet bulk enthalpy is a more dominant factor in determining the flight relevant arc-jet heating environment. Assuming a bulk enthalpy of $4 \mathrm{MJ} / \mathrm{kg}$, the HEART Type 12 fully-catalytic flight relevant arc-jet environment profile along with its flight pressure profile was successfully calibrated in the LCAT arc-jet (see Fig. 21.) Note that the fully-catalytic arc-jet environment heating indicator was relatively insensitive to the bulk enthalpy variations.

The ability to closely predict the flight relevant arc-jet environment for HEART mission provides a more suitable approach in developing new generations of thermal protection systems as the missionspecific survivability of the these non-ablating flexible systems are strongly influenced by the rate of change of heat flux.

\section{Conclusion}

A methodology for estimating arc-jet free stream condition for a flight relevant aerothermodynamic condition representing the surface calibration probe values was introduced. The presented technique was applied for the support of the HIAD earth atmospheric reentry test (HEART) vehicle. Based on series of computational analyses, a new arc-jet sample holder was designed specifically for the flexible thermal protection system testing. With the employment of high fidelity computational analyses and

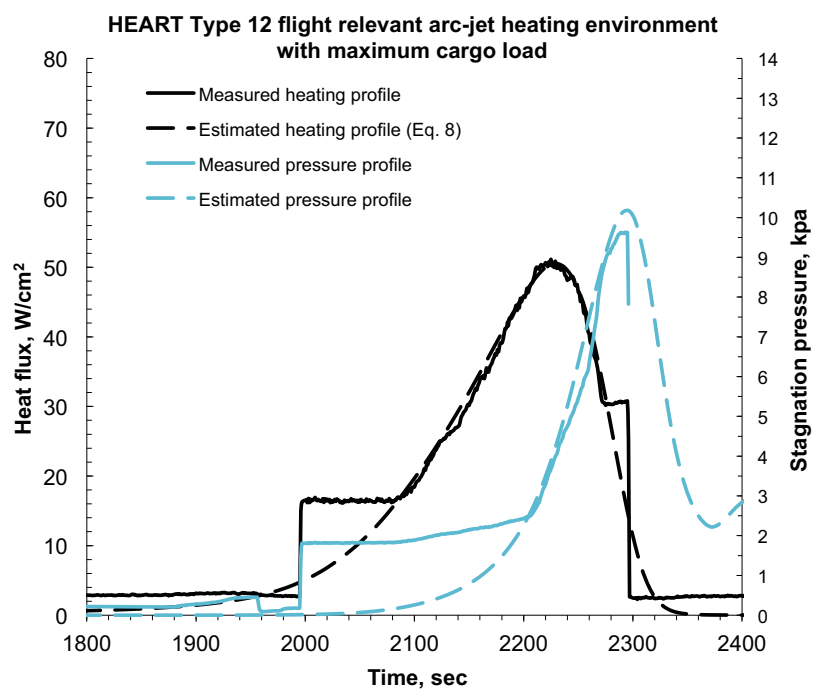

Figure 21. HEART flight relevant measured vs. estimated arc-jet aeroheating indicators. 
mine arc-jet equivalent aeroheating indicators cor-

responding to the flight aeroheating indicators.

\section{Acknowledgments}

This project was supported by the Hypersonic Inflatable Aerodynamic Decelerator (HIAD) and the HIAD Earth Atmospherc Reentry Test (HEART) projects. The authors would also like to thank John R. Simms and Matthew P. Kardell at the Boeing LCAT facility who successfully programed the arc heater controller to match the arc-jet heat flux and flight surface pressure from the presented correlations through the entire duration of the flight. The thanks would also go to the reviewers for their thorough review of the paper and constructive comments.

\section{References}

\footnotetext{
${ }^{1}$ Bruce III, W. E., Mesick, N. J., Ferlemann, P. G., Siemers III, P. M., Del Corso, J. A., Hughes, S. J., Tobin, S.A., Kardell, M. P., "Aerothermal Ground Testing of Flexible Thermal Protection Systems for Hypersonic Inflatable Aerodynamic Decelerators", 9th International Planetary Probe Workshop, 16-22 June 2012, Toulouse, France.

${ }^{2}$ DelCorso, J. A., Cheatwood, F. M., Bruce III, W. E., Hughes, S. J., and Calomino, A. M., "Advanced High-Temperature Flexible TPS for Inflatable Arodynamic Decelerators", AIAA-2011-2510, May 2011.

${ }^{3}$ DelCorso J. A., Bruce III, W. E., Hughes, S. J., Dec, J. A., Rezin, M. D., Meador, M. B., Hiaquan, G., Fletcher, D. G., Calomino, A. M., and Cheatwood, F. M., "Flexible Thermal Protection System Development for Hypersonic Inflatable Aerodynamic Decelerators", 9th International Planetary Probe Workshop, 16-22 June 2012, Toulouse, France.

4 "Evaluation of the NASA arc-jet Capabilities to Support Mission Requirements", Office of the Chief Engineer, NASA/SP2010-577, May 2010.

${ }^{5}$ Zoby, V., "Effects of Corner Radius on Stagnation-Point Velocity Gradients on Blunt Axisymmetric Bodies", NASA TM X-1067, 1964.

${ }^{6}$ Sutton, Kenneth, and Graves, Randolph A., Jr., "A General Stagnation-Point Convective Heating Equation for Arbitrary Gas Mixtures", NASA TR-376, 1971.

${ }^{7}$ Gupta, R., Yos, J., Thompson, R.A., and Lee, K., "A Review of Reaction Rates and Thermodynamic and Transport Properties for an 11-Species Air Model for Chemical and Thermal Nonequilibrium Calculations to 30,000 K", NASA RP 1232, 1990.

${ }^{8}$ Wright, M., "Recommended Collision Integrals for Transport Property Computations Part 1: Air Species", AIAA Journal, Vol. 43, No. 12, pp. 2558-2564, 2005.

${ }^{9}$ Wright, M., "Recommended Collision Integrals for Transport Property Computations Part 2: Mars and Venus Entries", AIAA Journal, Vol. 45, No. 1, pp. 281-288, 2005.

${ }^{10}$ Gordon, S., and McBride, B.J., "Computer Program for Calculation of Complex Equilibrium Compositions and Applications", NASA RP 1311, 1994.

${ }^{11}$ Mazaheri, A.R., Gnoffo, P.A., Johnston, C.O., and Kleb, B., "LAURA 5 Users Manual", NASA TM-217800-2013, 2013.

${ }^{12}$ Hash, D., Olejniczak, J., Wright, M., Prabhu, D., Pulsonetti, M., Hollis, B., Gnoffo, P., Barnhardt, M., Nompelis, I., and Candler G., "Fire II Calculations for Hypersonic Nonequilibrium Aerothermodynamics Code Verifcation: DPLR, LAURA and US3D", AIAA Paper 2007-0605, 2007.

${ }^{13}$ Mazaheri, A., and Wood, W.A., "Re-Entry Aeroheating Analysis of Tile-Repair Augers for the Shuttle Orbiter", AIAA Paper 2007-4148, 2007.

${ }^{14}$ Mazaheri, A., and Wood, W.A., "Heating Augmentation for Short Hypersonic Protuberances", Journal of Spacecraft and Rockets, Vol. 46, No. 2, 2009, pp.284-291.

${ }^{15}$ Dyakonov, A.A., Schenenberger, M., Scallian, W.I., Van-Norman, J.W., Novak, L.A, and Tang, C.Y., "Aerodynamic Interference Due to MSL Reaction Control System”, AIAA Paper 2009-1030, 2009.

${ }^{16}$ Johnston, C.O., Gnoffo, P.A., and Mazaheri, A., "A Study of Ablation-Flowfield Coupling Relevant to the Orion Heatshield", AIAA Paper 2009-4318, 2009.

${ }^{17}$ Mazaheri, A., "HEART Aerothermodynamic Analysis", NASA TM-2012-217568, 2012.

${ }^{18}$ Wright, H., Cutright, A., Corliss, J., Bruce, W., Trombetta, D., Mazaheri, A., Coleman, M., Olds, A., and Hancock, S., "HEART Flight Test Overview", 9th International Planetary Probe Workshop, 16-22 June 2012, Toulouse, France.
} 